\title{
A REVISED VERSION OF THE PSYCHOTICISM SCALE
}

\author{
S. B. G. Eysenck, H. J. Eysenck and Paul BarretT \\ Department of Psychology, Institute of Psychiatry, De Crespigny Park, Denmark Hill, \\ London SES 8AF, England \\ (Received 28 June 1984)
}

\begin{abstract}
Summary - In view of certain psychometric deficiencies of the original Psychoticism scale, an attempt was made to improve the scale by adding new items. It was attempted to increase the internal reliability of the scale, improve the shape of the distribution and increase the mean and variance score. Two different studies are discussed. Reliabilities are now somewhat improved, distributions are closer to normal and mean scores are higher than on the old scale. Four new short 12 -item scales for the measurement of $P, E$, $\mathbf{N}$ and $\mathbf{L}$ are also given.
\end{abstract}

\section{INTRODUCTION}

The publication of Psychoticism as a Dimension of Personality (Eysenck and Eysenck, 1976) and the Eysenck Personality Questionnaire (EPQ; Eysenck and Eysenck, 1975) was accompanied by numerous criticisms of the psychometric properties of the P scale (Block, 1977a, b; Bishop, 1977), as well as other aspects of the concept itself; some of these were answered by Claridge and Birchall (1978), Eysenck (1977) and Eysenck and Eysenck (1977). A summary of the available evidence to date on all the points has been presented by Claridge (1981), and there is no intention here to discuss these issues any further. Our intention is to try and improve what are undoubtedly psychometric weaknesses in the $P$ scale of the EPQ, by designing new items, based on the development of the original concept, testing the relevance of these items by new factor-analytic studies and construct improved questionnaires in the hope of improving upon the original version of the P scale.

There are three major faults in the original $P$ scale which, while not apparently interfering too much with its validity in group comparisons, made individual application rather hazardous. The first of these faults is the low reliability of the scale, 0.74 for males and 0.68 for females. (These are internal reliabilities; test-retest reliabilities are rather higher, viz. 0.83 and 0.71 .) The second fault is the low range of scoring, with means of 3.78 for males and 2.63 for females. The fact that standard deviations were almost identical with means (3.09 and 2.36) indicates the third fault, namely the grossly skewed distribution of scores, which almost resembled a Poissonian distribution. The fact that in spite of these faults the scale was found to behave very consistently and predictably (Claridge, 1981) suggests that the validity was not depressed too much by these psychometric faults, but clearly improvements should be made if possible.

\section{SAMPLES AND METHODS}

Two studies were, in fact, carried out to this end. The first (A) used a 90-item questionnaire which contained the EPQ P scale plus possible new $P$ items, together with $12 \mathrm{E}$ and $13 \mathrm{~N}$ items selected from the EPQ. There were no L-scale items. The sample tested consisted of 384 males and 290 females, whose ages ranged from 17 to $70 \mathrm{yr}$, their respective age means being $40.01 \pm 14.39$ and $37.99 \pm 14.47 \mathrm{yr}$. Sample A was collected by random approach in the street and by house-tohouse circulation of questionnaires.

The second sample (B) used a 117-item questionnaire which contained all the 90 items of the EPQ plus almost all the possible new $\mathbf{P}$ items used for the questionnaire of Study A. This sample was collected in a more orthodox manner, with groups of students, teachers and other willing and varied $S$ s being approached to complete the questionnaire and returned by post. There were 408 males and 494 females aged $38.44 \pm 17.67$ and $31.80 \pm 15.84 \mathrm{yr}$, respectively, the range being the same as in Study A. 
In both studies the items were intercorrelated separately for males and females and the resulting matrices factor-analysed by principal components. In Study A, three factors were extracted and rotated through Varimax and then Promax, these being identified as P, E and N. In Study B, however, four factors were extracted and were similarly rotated using Direct Oblimin rotation. These were clearly identified as $\mathrm{P}, \mathrm{E}, \mathrm{N}$ and the $\mathrm{L}$ scale.

Both sets of loadings were scrutinized for suitable $P$ items to improve the original scale. Table 1 gives the 32 items which were finally chosen to make up the P scale of the EPQ-Revised (EPQ-R). It will be seen that only the $P$ loadings are given for Sample $A$, but all $P, E, N$ and $L$ loadings are given for Sample B. This is because of the few $\mathrm{E}$ and $\mathrm{N}$ items in Study A, and the complete absence of $\mathbf{L}$ items.

Table 1. Factor loadings on $P$ for Sample A and on P, E. N and L for Sample B for items on EPQ-R

\begin{tabular}{|c|c|c|c|c|c|c|c|c|c|c|}
\hline \multirow{3}{*}{$\begin{array}{l}\text { No. on } \\
\text { 100-item } \\
\text { EPQ-R }\end{array}$} & \multicolumn{5}{|c|}{ MALES } & \multicolumn{5}{|c|}{ FEMALES } \\
\hline & \multirow{2}{*}{$\begin{array}{c}\text { Sampie A } \\
(n=290) \\
P\end{array}$} & \multicolumn{4}{|c|}{$\begin{array}{l}\text { Sample B } \\
(n=408)\end{array}$} & \multirow{2}{*}{$\begin{array}{c}\text { Sample A } \\
(n=384) \\
\mathrm{P}\end{array}$} & & \multicolumn{2}{|c|}{$\begin{array}{l}\text { Sample B } \\
(n=494)\end{array}$} & \multirow[b]{2}{*}{$\mathbf{L}$} \\
\hline & & $\mathrm{P}$ & $\mathrm{E}$ & $\mathrm{N}$ & $\mathrm{L}$ & & $\mathbf{P}$ & $\mathrm{E}$ & $N$ & \\
\hline-2 & -0.34 & -0.38 & -0.11 & -0.02 & 0.14 & -0.19 & -0.25 & -0.14 & -0.01 & 0.22 \\
\hline-5 & -0.36 & -0.42 & 0.18 & 0.17 & -0.03 & -0.30 & -0.32 & 0.12 & 0.26 & -0.09 \\
\hline-7 & -0.43 & -0.32 & -0.18 & 0.17 & 0.11 & -0.36 & -0.30 & -0.11 & 0.24 & 0.18 \\
\hline-9 & -0.41 & -0.33 & -0.01 & -0.07 & -0.02 & -0.35 & -0.27 & -0.06 & -0.04 & -0.02 \\
\hline-12 & -0.31 & -0.47 & 0.05 & 0.15 & -0.02 & -0.15 & -0.26 & 0.01 & -0.01 & -0.20 \\
\hline-14 & -0.33 & -0.18 & -0.04 & 0.16 & 0.23 & -0.06 & -0.21 & -0.09 & 0.17 & 0.08 \\
\hline-18 & -0.38 & -0.28 & 0.08 & -0.05 & 0.25 & -0.38 & -0.43 & 0.08 & 0.05 & 0.31 \\
\hline-21 & -0.48 & -0.25 & 0.26 & 0.08 & 0.24 & -0.17 & -0.44 & 0.16 & 0.13 & 0.12 \\
\hline 25 & 0.26 & 0.30 & 0.13 & 0.08 & -0.22 & 0.32 & 0.41 & 0.07 & 0.07 & -0.19 \\
\hline 29 & 0.47 & 0.21 & 0.01 & -0.01 & -0.22 & $0.5 !$ & 0.39 & -0.02 & -0.11 & -0.11 \\
\hline 30 & 0.46 & 0.30 & 0.03 & 0.08 & -0.01 & 0.24 & 0.32 & 0.17 & 0.18 & 0.16 \\
\hline 34 & 0.31 & 0.29 & 0.11 & 0.25 & 0.11 & 0.32 & 0.28 & 0.11 & 0.25 & 0.15 \\
\hline 37 & 0.40 & 0.37 & 0.20 & 0.03 & -0.10 & 0.31 & 0.31 & 0.18 & 0.08 & -0.05 \\
\hline-41 & -0.55 & -0.37 & 0.26 & 0.05 & 0.21 & -0.26 & -0.44 & 0.16 & 0.17 & 0.18 \\
\hline 42 & 0.26 & 0.25 & 0.12 & 0.18 & -0.17 & 0.42 & 0.39 & 0.08 & -0.01 & -0.14 \\
\hline 48 & 0.33 & 0.43 & -0.04 & 0.01 & 0.12 & 0.47 & 0.45 & -0.08 & 0.08 & 0.07 \\
\hline 50 & 0.34 & 0.22 & 0.04 & -0.04 & -0.09 & 0.40 & 0.32 & 0.06 & -0.06 & -0.01 \\
\hline-54 & -0.46 & -0.37 & 0.36 & -0.07 & 0.04 & -0.31 & -0.33 & 0.12 & -0.02 & -0.10 \\
\hline 56 & 0.05 & 0.39 & -0.08 & -0.03 & 0.18 & 0.18 & 0.34 & 0.02 & 0.18 & 0.31 \\
\hline-59 & -0.53 & -0.42 & -0.12 & 0.17 & 0.09 & -0.34 & -0.39 & -0.09 & 0.10 & -0.02 \\
\hline-64 & -0.27 & -0.19 & -0.07 & 0.04 & 0.09 & -0.22 & -0.32 & 0.03 & 0.03 & 0.05 \\
\hline-68 & -0.26 & -0.27 & 0.06 & -0.08 & -0.20 & -0.17 & -0.32 & 0.02 & -0.10 & -0.27 \\
\hline 73 & 0.32 & 0.30 & 0.10 & 0.30 & 0.12 & 0.29 & 0.40 & 0.08 & 0.20 & 0.26 \\
\hline 75 & 0.44 & 0.32 & 0.08 & 0.02 & -0.07 & 0.35 & 0.30 & 0.08 & -0.04 & -0.03 \\
\hline-79 & -0.51 & -0.39 & -0.02 & 0.04 & 0.11 & -0.31 & -0.34 & -0.06 & -0.04 & 0.11 \\
\hline-81 & -0.27 & -0.27 & -0.16 & -0.05 & 0.27 & -0.20 & -0.31 & -0.25 & -0.07 & 0.24 \\
\hline-85 & -0.19 & -0.40 & 0.01 & -0.29 & -0.25 & -0.44 & -0.20 & 0.14 & -0.25 & -0.10 \\
\hline-88 & -0.50 & -0.19 & 0.11 & -0.02 & 0.26 & -0.46 & -0.37 & 0.07 & 0.08 & 0.19 \\
\hline 91 & 0.36 & 0.53 & 0.17 & 0.16 & 0.09 & 0.36 & 0.44 & 002 & 019 & 024 \\
\hline 95 & 0.14 & 0.38 & 0.19 & 0.26 & 0.20 & 0.33 & 0.26 & 0.03 & 0.22 & 0.14 \\
\hline-96 & -0.41 & -0.34 & -0.04 & -0.05 & -0.06 & -0.36 & -0.38 & 0.06 & 0.04 & -0.01 \\
\hline-99 & -0.29 & -0.36 & -0.02 & 0.04 & 0.04 & -0.20 & -0.14 & -0.04 & -0.03 & -0.14 \\
\hline
\end{tabular}

\section{RESULTS}

Although Sample A were somewhat older than Sample B (especially the females), and the collection of the data was somewhat different, the P-scale means and standard deviations were pooled. These are given, for different age groups, in Table 2 and contain Ss from Samples A and B combined for P, but only from Sample B for E, N and L. However, just as a matter of interest, Table 3 gives the actual means and standard deviations on $\mathrm{P}$ obtained by each of the age groups in Samples A and B, respectively.

The scoring key on which these mcans werc calculated is given in Table 4, the item numbers referring to questions on the 100 item EPQ-R given in Appendix 1. There are now 32 items on the new $P$ scale, i.e. 7 more than in the EPQ $P$ scale and very slight changes to $E$ and $N$ were made so that the former has 23 and the latter 24 items, leaving $L$ with the original 21 items. The total number of items, therefore, is now 100. 
Table 2. Means and standard deviations of $P, E, N$ and $L$ for different age groups on the EPQ-R

\begin{tabular}{|c|c|c|c|c|c|c|c|c|c|c|}
\hline \multirow{3}{*}{$\begin{array}{c}\text { Age } \\
\text { group } \\
(\mathrm{yr})\end{array}$} & \multicolumn{3}{|c|}{ Samples A + B } & \multicolumn{7}{|c|}{ Sample B } \\
\hline & \multirow[b]{2}{*}{$n$} & \multicolumn{2}{|c|}{$\mathbf{P}$} & \multirow[b]{2}{*}{$n$} & \multicolumn{2}{|c|}{$\mathbf{E}$} & \multicolumn{2}{|c|}{$\mathbf{N}$} & \multicolumn{2}{|c|}{$\mathbf{L}$} \\
\hline & & $\bar{X}$ & $\mathrm{SD}$ & & $\bar{X}$ & $\mathrm{SD}$ & $\bar{X}$ & SD & $\bar{X}$ & $\mathrm{SD}$ \\
\hline & & & & & Males & & & & & \\
\hline $16-20$ & 120 & 9.57 & 5.26 & 108 & 15.97 & 5.26 & 11.12 & 5.68 & 5.37 & 4.18 \\
\hline $21-30$ & 148 & 8.65 & 4.56 & 64 & 14.50 & 5.64 & 11.08 & 5.37 & 5.53 & 3.39 \\
\hline $31-40$ & 117 & 6.69 & 3.58 & 53 & 11.92 & 5.67 & 11.92 & 5.70 & 6.66 & 3.59 \\
\hline $41-50$ & 107 & 7.00 & 4.65 & 55 & 11.91 & 5.09 & 11.22 & 5.95 & 7.04 & 3.87 \\
\hline $51-60$ & 110 & 5.28 & 3.59 & 69 & 8.94 & 5.75 & 9.43 & 6.27 & 9.14 & 4.29 \\
\hline $61-70$ & 91 & 4.87 & 3.55 & 59 & 8.68 & 5.71 & 8.32 & 5.07 & 10.05 & 3.65 \\
\hline Total & 693 & 7.19 & 4.60 & 408 & 12.51 & 6.00 & 10.54 & 5.81 & 7.10 & 4.28 \\
\hline & & & & & Females & & & & & \\
\hline $16-20$ & 203 & 7.06 & 4.11 & 161 & 15.47 & 4.99 & 14.03 & 4.85 & 5.45 & 3.25 \\
\hline $21-30$ & 256 & 6.20 & 3.86 & 159 & 14.17 & 4.68 & 12.53 & 4.78 & 6.33 & 3.82 \\
\hline $31-40$ & 135 & 5.87 & 3.72 & 38 & 13.55 & 4.93 & 11.71 & 4.94 & 6.79 & 3.74 \\
\hline $41-50$ & 109 & 4.62 & 3.05 & 50 & 12.36 & 4.95 & 10.94 & 5.92 & 8.02 & 3.88 \\
\hline $51-60$ & 102 & 4.05 & 3.21 & 45 & 13.62 & 5.47 & 11.31 & 5.36 & 8.82 & 3.97 \\
\hline $61-70$ & 73 & 4.19 & 3.26 & 41 & 12.15 & 5.08 & 9.98 & 5.51 & 11.20 & 3.09 \\
\hline Total & 878 & 5.73 & 3.85 & 494 & 14.14 & 5.06 & 12.47 & 5.22 & 6.88 & 3.97 \\
\hline
\end{tabular}

Table 3. Means and standard deviations for the $P$ scale only for Samples $A, B$ and $(A+B)$ combined

\begin{tabular}{|c|c|c|c|c|c|c|c|c|c|}
\hline \multirow{2}{*}{$\begin{array}{c}\text { Age } \\
\text { group } \\
(\mathrm{yr})\end{array}$} & \multicolumn{3}{|c|}{ Sample B } & \multicolumn{3}{|c|}{ Sample A } & \multicolumn{3}{|c|}{ Samples B + A } \\
\hline & $n$ & $\bar{X}$ & $\mathrm{SD}$ & $n$ & $\bar{X}$ & SD & $n$ & $\bar{X}$ & SD \\
\hline \multicolumn{10}{|c|}{ Males } \\
\hline $16-20$ & 108 & 9.31 & 5.06 & 12 & 11.92 & 6.36 & 120 & 9.57 & 5.26 \\
\hline $21-30$ & 64 & 9.08 & 4.63 & 84 & 8.32 & 4.48 & 148 & 8.65 & 4.56 \\
\hline $31-40$ & 53 & 7.19 & 3.44 & 64 & 6.27 & 3.64 & 117 & 6.69 & 3.58 \\
\hline $41-50$ & 55 & 7.98 & 4.13 & 52 & 5.96 & 4.94 & 107 & 7.00 & 4.65 \\
\hline $51-60$ & 69 & 5.71 & 3.85 & 41 & 4.56 & 2.96 & 110 & 5.28 & 3.59 \\
\hline $61-70$ & 59 & 5.34 & 3.60 & 32 & 4.00 & 3.28 & 91 & 4.87 & 3.55 \\
\hline Total & 408 & 7.63 & 4.57 & 285 & 6.55 & 4.58 & 693 & 7.19 & 4.60 \\
\hline \multicolumn{10}{|c|}{ Females } \\
\hline $16-20$ & 161 & 6.98 & 4.15 & 42 & 7.36 & 3.94 & 203 & 7.06 & 4.11 \\
\hline $21-30$ & 159 & 6.30 & 4.16 & 97 & 6.04 & 3.30 & 256 & 6.20 & 3.86 \\
\hline $31-40$ & 38 & 6.61 & 3.90 & 97 & 5.58 & 3.61 & 135 & 5.87 & 3.72 \\
\hline $41-50$ & 50 & 5.12 & 3.27 & 59 & 4.19 & 2.77 & 109 & 4.62 & 3.05 \\
\hline $51-60$ & 45 & 4.80 & 3.16 & 57 & 3.46 & 3.13 & 102 & 4.05 & 3.21 \\
\hline $61-70$ & 41 & 5.00 & 3.48 & 32 & 3.16 & 2.61 & 73 & 4.19 & 3.26 \\
\hline Total & 494 & 6.18 & 4.00 & 384 & 5.16 & 3.56 & 878 & 5.73 & 3.85 \\
\hline
\end{tabular}

Table 4. Scoring key for the EPQ-R (items numbered as for the 100-item questionnaire)

(D)

YES: $25,29,30,34,37,42,48,50,56,73,75,91,95$

NO: $2,5,7,9,12,14,18,21,41,54,59,64,68,79,81,85,88,96,99$

()

YES: $1,6,11,16,20,28,36,40,45,51,55,58,61,63,67,69,72,78,90,94$ NO: $24,33,47$

(1)

YES: $3,8,13,17,22,26,31,35,38,4346,52,60,65,70,74,76,80,83,84,87,92,97,100$

(1)

YES: $15,23,39,62,86,98$

NO $4,10,19,27,32,44,49,53,57,66,71,77,82,89,93$ 
It should be mentioned that there were 6 items from the original 25 -item EPQ P scale, which have been omitted from the present revised scale. These were:

"Do you lock up your house carefully at night?"

"Do you believe insurance schemes are a good idea?"

"Do people who drive carefully annoy you?"

"When you catch a train do you often arrive at the last minute?"

"Do your friendships break up easily without it being your fault?"

and

"Do you sometimes like teasing animals?"

The main reason for these omissions was the lack of consistent loadings on the P factor.

However, 13 new $P$ items were incorporated in to the $P$ scale which, along with 19 of the original EPQ $P$ scale items now totals 32 items. In addition, two new $E$ items warranted inclusion in the new $E$ scale and one extra $\mathrm{N}$ item was added to the $\mathrm{N}$ scale, leaving $\mathrm{L}$ at the original 21 items.

Reliabilities ( $\alpha$-coefficients) and intercorrelations of the scales are given in Table 5 . It will be noted that separate reliabilities for $\mathrm{P}$ are given for Samples $\mathrm{A}$ and B. For interest, the correlations between the new P scale (EPQ-R) and that of the EPQ were calculated and the values were 0.88 for males and 0.81 for females (Sample B only).

Finally, it seemed desirable to try to devise a short scale of the EPQ-R for use when time is very limited. Twelve items were chosen from each of the scales and the short scale questionnaire is given in Appendix 2. The means and standard deviations of all the age groups are given in Table 6. Again, as with the longer scale, Table 6 gives the $P$ means and standard deviations of Samples A and $B$ pooled, while Table 7 shows the individual age group means for the separate samples on $P$.

Reliabilities for both samples are given in Table 8 and also intercorrelations of the scales for Sample B. The scoring key on Table 9 gives item numbers to correspond with the 48 -item short scale given in Appendix 2.

Table 5. Reliabilities of P (Sample A), and P, E, N and L (Sample B) (intercorrelations of P, E, N and L for Sample B only)

\begin{tabular}{|c|c|c|c|c|c|c|c|c|}
\hline & \multirow{2}{*}{$\frac{\text { Sample A }}{\mathbf{P}}$} & \multicolumn{4}{|c|}{ Reliabilities } & & \multicolumn{2}{|c|}{$\begin{array}{l}\text { Intercorrelations } \\
\text { (Sample B only) }\end{array}$} \\
\hline & & $\mathbf{P}$ & $\mathrm{E}$ & $\mathbf{N}$ & L & & Males & Females \\
\hline Males & 0.81 & 0.78 & 0.90 & 0.88 & 0.82 & $P E$ & 0.23 & 0.14 \\
\hline Females & 0.73 & 0.76 & 0.85 & 0.85 & 0.79 & $\begin{array}{l}\text { PN } \\
\text { PL } \\
\text { EN } \\
\text { EL } \\
\text { NL }\end{array}$ & $\begin{array}{r}0.19 \\
-0.34 \\
0.02 \\
-0.32 \\
-0.25\end{array}$ & $\begin{array}{r}0.06 \\
-0.16 \\
-0.07 \\
-0.19 \\
-0.26\end{array}$ \\
\hline
\end{tabular}

Table 6. Means and standard deviations of $P, E, N$ and $L$ for different age groups on the short scale of the EPQ-R

\begin{tabular}{|c|c|c|c|c|c|c|c|c|c|c|}
\hline \multirow{3}{*}{$\begin{array}{c}\text { Age } \\
\text { group } \\
(y r)\end{array}$} & \multicolumn{3}{|c|}{ Samples $(A+B)$} & \multicolumn{7}{|c|}{ Sample B } \\
\hline & \multirow[b]{2}{*}{$n$} & \multicolumn{2}{|c|}{$\mathbf{P}$} & \multirow[b]{2}{*}{$n$} & \multicolumn{2}{|l|}{$\mathrm{E}$} & \multicolumn{2}{|c|}{$\mathbf{N}$} & \multicolumn{2}{|c|}{$\mathrm{L}$} \\
\hline & & $\bar{x}$ & $\mathrm{SD}$ & & $\bar{x}$ & $\mathrm{SD}$ & $\bar{x}$ & $\mathrm{SD}$ & $\bar{X}$ & $\mathrm{SD}$ \\
\hline \multicolumn{11}{|c|}{ Males } \\
\hline $16-20$ & 120 & 4.16 & 2.43 & $10 \overline{8}$ & 8.16 & 3.30 & 5.03 & 3.41 & 2.69 & 2.61 \\
\hline $21-30$ & 148 & 3.57 & 2.29 & 64 & 7.42 & 3.44 & 5.17 & 3.35 & 2.92 & 2.00 \\
\hline $31-40$ & 117 & 2.82 & 1.84 & 53 & 6.40 & 3.85 & 5.75 & 3.46 & 3.58 & 2.28 \\
\hline $41-50$ & 107 & 2.93 & 2.18 & 55 & 6.18 & 3.34 & 5.24 & 3.41 & 3.98 & 2.51 \\
\hline $51-60$ & 110 & 2.28 & 1.61 & 69 & 4.48 & 3.69 & 4.49 & 3.70 & 5.16 & 2.83 \\
\hline $61-70$ & 91 & 2.36 & 2,06 & 59 & 4.24 & 3.40 & 4.14 & 3.04 & 5.61 & 2.36 \\
\hline Total & 693 & 3.08 & 2.20 & 408 & 6.36 & 3.80 & 4.95 & 3.44 & 3.86 & 2.71 \\
\hline \multicolumn{11}{|c|}{ Females } \\
\hline $16-20$ & 203 & 2.79 & 1.95 & 161 & 8.40 & 3.23 & 6.66 & 3.05 & 2.75 & 2.03 \\
\hline $21-30$ & 256 & 2.56 & 1.95 & 159 & 7.60 & 3.02 & 5.93 & 2.89 & 3.34 & 2.41 \\
\hline $31-40$ & 135 & 2.37 & 1.80 & 38 & 7.37 & 3.18 & 5.50 & 2.92 & 3.76 & 2.38 \\
\hline $41-50$ & 109 & 2.05 & 1.63 & 50 & 6.48 & 3.20 & 5.06 & 3.37 & 4.26 & 2.46 \\
\hline $51-60$ & 102 & 1.72 & 1.67 & 45 & 7.22 & 3.64 & 5.36 & 3.44 & 4.96 & 2.70 \\
\hline $61-70$ & 73 & 1.76 & 1.74 & 41 & 6.46 & 3.24 & 4.78 & 3.28 & 6.56 & 2.14 \\
\hline Total & 878 & 2.35 & 1.88 & 494 & 7.60 & 3.27 & 5.90 & 3.14 & 3.69 & 2.55 \\
\hline
\end{tabular}


Table 7. Means and standard deviations for the short-scale EPQ-R P scale only for Samples A, B and (A + B) combined

\begin{tabular}{|c|c|c|c|c|c|c|c|c|c|}
\hline \multirow{2}{*}{$\begin{array}{c}\text { Age } \\
\text { group } \\
(y r)\end{array}$} & \multicolumn{3}{|c|}{ Sample B } & \multicolumn{3}{|c|}{ Sample $A$} & \multicolumn{3}{|c|}{ Samples B + A } \\
\hline & $n$ & $\bar{X}$ & $\mathrm{SD}$ & $n$ & $\bar{X}$ & $\mathrm{SD}$ & $n$ & $\bar{X}$ & $\mathrm{SD}$ \\
\hline \multicolumn{10}{|c|}{ Males } \\
\hline $16-20$ & 108 & 4.05 & 2.27 & 12 & 5.17 & 3.39 & 120 & 4.16 & 2.43 \\
\hline $21-30$ & 64 & 3.83 & 2.26 & 84 & 3.38 & 2.29 & 148 & 3.57 & 2.29 \\
\hline $31-40$ & 53 & 3.23 & 1.82 & 64 & 2.48 & 1.79 & 117 & 2.82 & 1.84 \\
\hline $41-50$ & 55 & 3.44 & 2.03 & 52 & 2.40 & 2.21 & 107 & 2.93 & 2.18 \\
\hline $51-60$ & 69 & 2.38 & 1.72 & 41 & 2.12 & 1.38 & 110 & 2.28 & 1.61 \\
\hline $61-70$ & 59 & 2.61 & 2.16 & 32 & 1.91 & 1.76 & 91 & 2.36 & 2.06 \\
\hline Total & 408 & 3.33 & 2.18 & 285 & 2.73 & 2.19 & 693 & 3.08 & 2.20 \\
\hline \multicolumn{10}{|c|}{ Females } \\
\hline $16-20$ & 161 & 2.84 & 1.99 & 42 & 2.60 & 1.75 & 203 & 2.79 & 1.95 \\
\hline $21-30$ & 159 & 2.74 & 2.08 & 97 & 2.27 & 1.67 & 256 & 2.56 & 1.95 \\
\hline $31-40$ & 38 & 2.68 & 2.08 & 97 & 2.25 & 1.66 & 135 & 2.37 & 1.80 \\
\hline $41-50$ & 50 & 2.34 & 1.66 & 59 & 1.80 & 1.57 & 109 & 2.05 & 1.63 \\
\hline $51-60$ & 45 & 1.98 & 1.54 & 57 & 1.51 & 1.74 & 102 & 1.72 & 1.67 \\
\hline $61-70$ & 41 & 2.20 & 1.88 & 32 & 1.19 & 1.33 & 73 & 1.76 & 1.74 \\
\hline Total & 494 & 2.61 & 1.97 & 384 & 2.02 & 1.69 & 878 & 2.35 & 1.88 \\
\hline
\end{tabular}

Table 8. Short-scale reliabilities of $P$ (Sample A) and P, E, N and L (Sample B) (short-scale intercorrelations of P, E, N and L for Sanple B only)

\begin{tabular}{|c|c|c|c|c|c|c|c|c|}
\hline & \multicolumn{2}{|c|}{$\underline{\text { Reliabilities }}$} & \multicolumn{3}{|c|}{ Sample B } & & \multicolumn{2}{|c|}{$\frac{\text { Intercorrelations }}{\text { (Sample B only) }}$} \\
\hline & $\mathbf{P}$ & $\mathbf{P}$ & $E$ & $N$ & $\mathbf{L}$ & & Males & Females \\
\hline Males & 0.68 & 0.62 & 0.88 & 0.84 & 0.77 & PE & 0.07 & 0.04 \\
\hline \multirow{5}{*}{ Females } & 0.51 & 0.61 & 0.84 & 0.80 & 0.73 & PN & 0.14 & 0.04 \\
\hline & & & & & & $\mathrm{PL}$ & -0.23 & -0.13 \\
\hline & & & & & & $\mathrm{EN}$ & -0.09 & -0.10 \\
\hline & & & & & & $\mathrm{EL}$ & -0.21 & -0.12 \\
\hline & & & & & & NL & -0.16 & -0.19 \\
\hline
\end{tabular}

Table 9. Short-scale EPQ-R scoring key

\begin{tabular}{l}
\hline (P) \\
YES: $10,14,22,31,39$ \\
NO: $2,6,18,26,28,35,43$ \\
(E) \\
YES: $3,7,11,15,19,23,32,36,44,48$ \\
NO: 27,41 \\
(1) \\
YES: $1,5,9,13,17,21,25,30,34,38,42,46$ \\
(1) \\
YES: $4,16,45$ \\
NO: $8,12,20,24,29,33,37,40,47$
\end{tabular}

\section{DISCUSSION}

Since, admittedly, the P scale of the EPQ suffered from several psychometric shortcomings, an attempt has now been made to rectify some of these. The three main areas of criticism have been listed in the Introduction as: (1) low reliability, (2) low range of scoring and (3) grossly skewed distribution.

The reliabilities (see Table 5) are 0.78 for males and 0.76 for females which contrasts with 0.74 for males and 0.68 for females as quoted in the EPQ manual (Eysenck and Eysenck, 1975). Although this is still not as high as the reliabilities achieved for $\mathrm{E}, \mathrm{N}$ and $\mathrm{L}$, it must be remembered that the $P$ scale taps several different facets (hostility, cruelty, lack of empathy, non-conformism etc.) which 
may hold reliabilities lower than would be true of a scale like $\mathrm{E}$ which comprises largely sociability and activity items only (Cattell and Tsujioka, 1964). At any rate, the new reliabilities are now acceptable and are certainly an improvement on those of the EPQ P scale.

The low range of scoring of the 25 -item $P$ scale was a great disadvantage in that means of $3.78 \pm$ 3.09 for males and $2.63 \pm 2.36$ for females, quoted in the manual of the EPQ, gave very little room for differentiation. The nature of the scale, unfortunately, is such that most discriminating items are somewhat 'way out' for most people. The original PEN P scale contained even more paranoid and schizoid type items than the EPQ P scale, and some criticism of this latter scale from researchers like Claridge (1981) dwells on the better discrimination of the old PEN P scale as far as schizophrenics are concerned. Hopefully the present changes of the $\mathrm{P}$ scale will not further reduce the usefulness of the EPQ-R for work with schizophrenics, but this remains to be seen when the scale is applied to clinical groups in due course. Meanwhile, Table 2, shows means of $7.19 \pm 4.60$ for males and $5.73 \pm 3.85$ for females; this contrasts with $4.15 \pm 3.42$ for males and $2.97 \pm 2.59$ for females when the same groups are scored for $P$ on the original 25 items of the EPQ. This difference seems a considerable improvement giving greater leeway in scoring.

Finally, the question of skewness and kurtosis of distribution was investigated. Since all 25 original EPQ P scale items are contained in the questionnaires used in both Studies A and B, it was possible to compute the moments for this scale as well as for the 32-item new $P$ scale form. Both distributions, of combined Studies A and B Ss, were plotted as histograms and are given in Figs 1 and 2. It can be seen that there is a somewhat improved skewness in the new distribution, especially so for the females, and this is reflected in the drop in both skewness and kurtosis values listed in the figures. It would be unreasonable to expect a dramatic normalizing of the distribution for the $\mathbf{P}$ scale, since the scale itself must inevitably, by its very nature, constitute some departure from normality. This is so, not only by reason of the type of items which differentiate high and low $\mathrm{P}$ scorers, but also highlights a proven hallmark of high $\mathrm{P}$ scorers to be uncooperative as far as helping researchers with questionnaire replies. "Did you mind filling in this form?" gives consistent loadings on $\mathrm{P}$ and suggests that high $\mathrm{P}$ scorers would be much less likely to complete a personality questionnaire than low $\mathrm{P}$ scorers. Thus, however improved the $\mathrm{P}$ scale, it seems likely to be doomed to a slightly $\mathrm{J}$-shaped distribution as long as high $\mathrm{P}$ scorers are able to decline to cooperate.

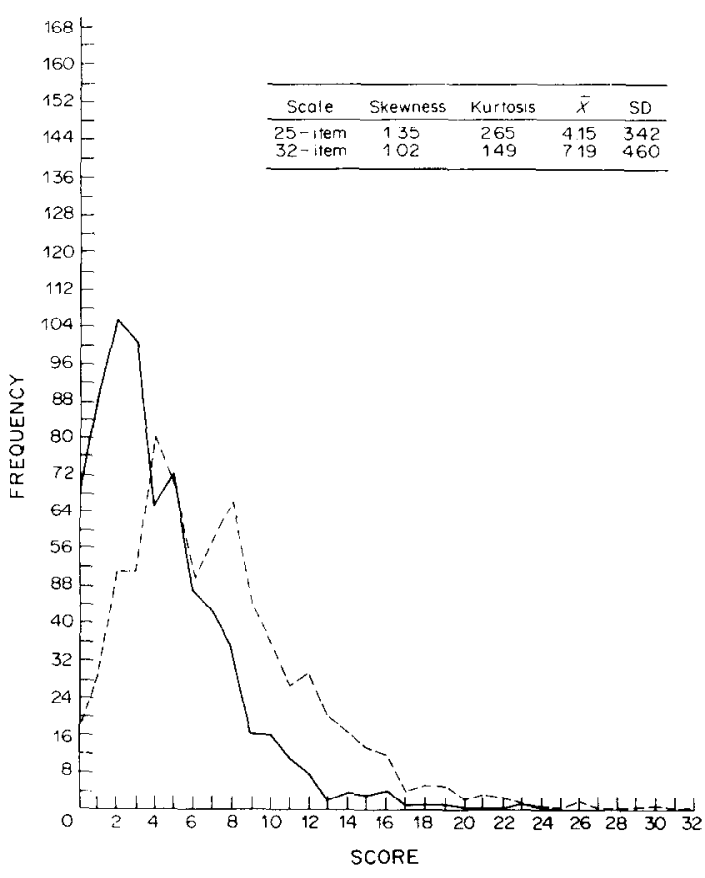

Fig. 1. Distributions of combined Studies $\mathrm{A}+\mathrm{B}$ for males $(n=693)$. _- 25-item scale; $\ldots-$ - 32-item scale.

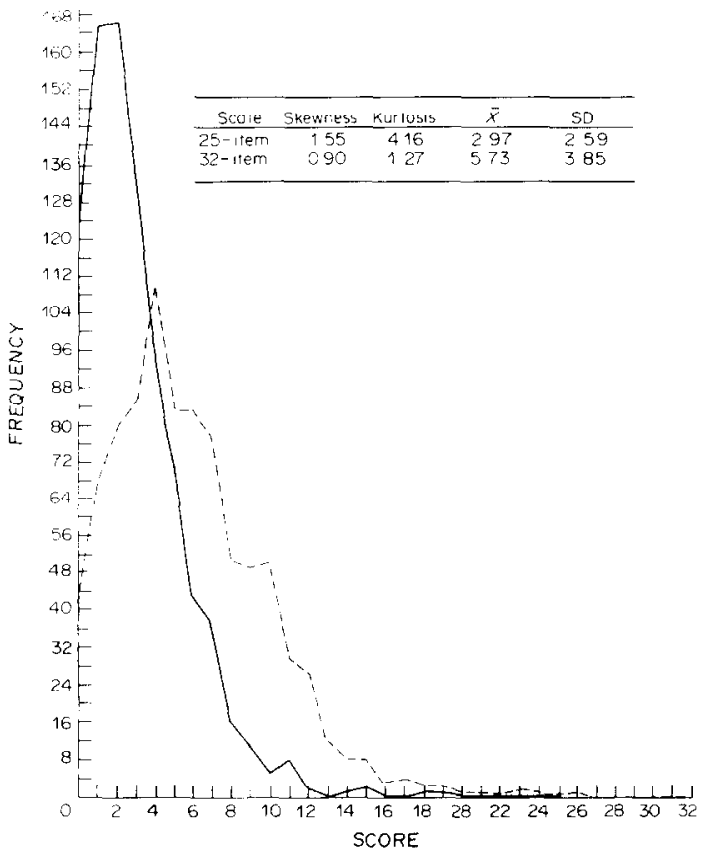

Fig. 2. Distribution of combined Studies $\mathrm{A}+\mathrm{B}$ for females $(n=878)$. 25 -item scale; - - 32-item scale. 
Nevertheless, we feel that all these areas of improvement which we set out to tackle, have yielded some success and, hopefully, researchers may try the new questionnaire out in future studies.

Acknowledgements--We are indebted to Dr G. Easting, Mr P. R. Pearson and Dr C. Gosselin for help in the collection of the data. Also, our thanks to Mrs Maeve Denby and the British Humanist Association for contributing Ss to our data. Our thanks also to Jackie Marshall for computational help.

\section{REFERENCES}

Bishop D. V. M. (1977) The P scale and psychosis. J. abnorm. Psychol. 86, 127-134.

Block J. (1977a) P scale and psychosis: continued concerns. J. abnorm. Psychol. 85, 431-434.

Block J. (1977b) The Eysencks and psychoticism. J. abnorm. Psychol. 86, 656- .

Cattell R. B. and Tsujioka B. (1964) The importance of factor trueness and of validity versus homogeneity and orthogonality in test scales. Educ. psychol Measur. 24, 3-30.

Claridge G. (1981) Psychoticism. In Dimensions of Personality (Edited by Lynn R.), pp. 79-110. Pergamon Press, New York.

Claridge G. and Birchall P. (1978) Bishop, Eysenck, Block and psychoticism. J. abnorm. Psychol. 87, 664-668.

Eysenck H. J. (1977) Psychosis and psychoticism: a reply to Bishop. J. ahnorm. Psychol. 86, 427-430.

Eysenck H. J. and Eysenck S. B. G. (1975) Manual of the Eysenck Personality Questionnaire. Hodder \& Stoughton, London.

Eysenck H. J. and Eysenck S. B. G. (1976) Psychoticism as a Dimension of Personality. Hodder \& Stoughton, London.

Eysenck H. J. and Eysenck S. B. G. (1977) Block and psychoticism. J. abnorm. Psychol. 86, 651-652.

\section{APPENDIX 1}

$E P Q-R$

Occupation

Age $\ldots \ldots \ldots$ Sex $\ldots \ldots \ldots \ldots$

Instructions: Please answer each question by putting a circle around the 'YES' or the 'NO' following the question. There are no right or wrong answers, and no trick questions. Work quickly and do not think too long about the exact meaning of the questions.

\section{PLEASE REMEMBER TO ANSWER EACH QUESTION}

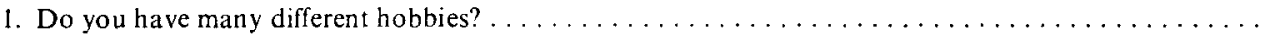

2. Do you stop to think things over before doing anything?

3. Does your mood often go up and down?.

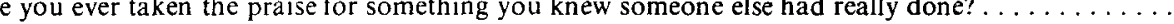

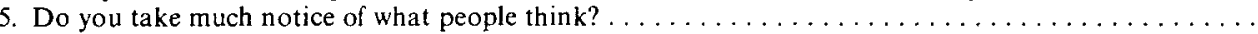

6. Are you a talkative person?

7. Would being in debt worry you?

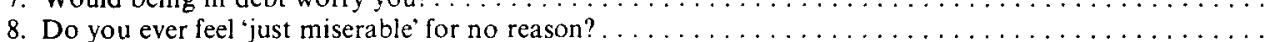

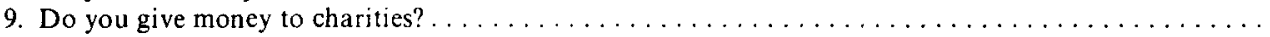

10. Were you ever greedy by helping yourself to more than your share of anything? . . . . . . . .

11. Are you rather lively?

12. Would it upset you a lot to see a child or an animal suffer? . . . . . . . . . . . . . . .

13. Do you often worry about things you should not have done or said? $\ldots \ldots \ldots \ldots \ldots \ldots \ldots \ldots$

14. Do you dislike people who don't know how to behave themselves? . . . . . . . . . . . . . . .

15. If you say you will do something, do you always keep your promise no matter how inconvenient it

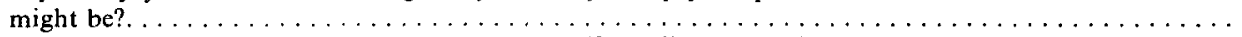

16. Can you usually let yourself go and enjoy yourself at a lively party? $\ldots \ldots \ldots \ldots \ldots \ldots \ldots \ldots$

17. Are you an irritable person?

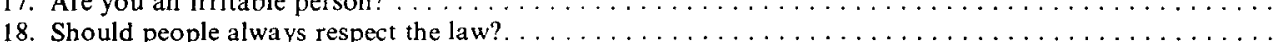

19. Have you ever blamed someone for doing something you knew was really your fault? . . . . . . . .

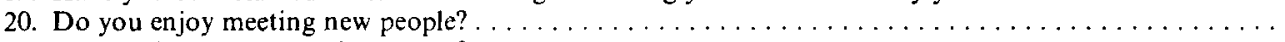

21. Are good manners very important?

22. Are your feelings easily hurt?.

23. Are all your habits good and desirable ones?.

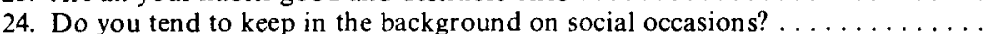

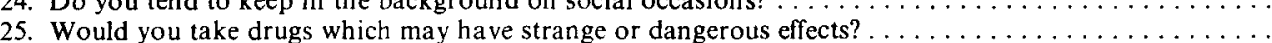

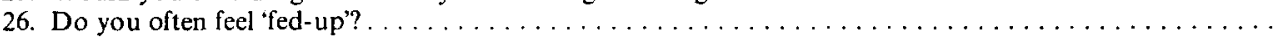

27. Have you ever taken anything (even a pin or button) that belonged to someone else? . . . . . . . .

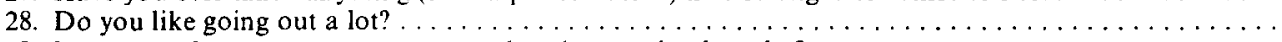

29. Do you prefer to go your own way rather than act by the rules? $\ldots \ldots \ldots \ldots \ldots \ldots \ldots \ldots \ldots \ldots$

30. Do you enjoy hurting people you love?. .

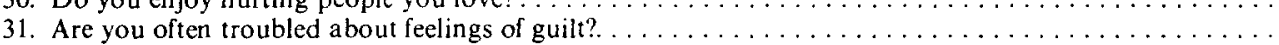

32. Do you sometimes talk about things you know nothing about? .

YES NO

YES NO

YES NO

YES NO

YES NO

YES NO

YES NO

YES NO

YES NO

YES NO

YES NO

YES NO

YES NO

YES NO

YES NO

YES NO

YES NO

YES NO

YES NO

YES NO

YES NO

YES NO

YES NO

YES NO

YES NO

YES NO

YES NO

YES NO

YES NO

YES NO

YES NO

YES NO 
continued

33. Do you prefer reading to ineeting people?

34. Do you have enemies who want to harm you?

35. Would you call yourself a nervous person?

36. Do you have many friends?.

37. Do you enjoy practical jokes that can sometimes really hurt people?

38. Are you a worrier?.

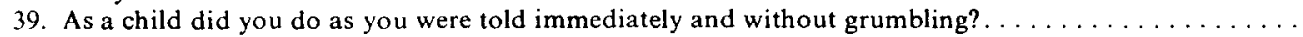

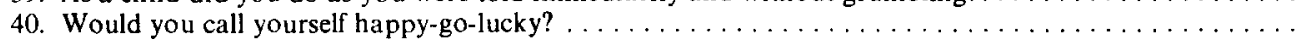

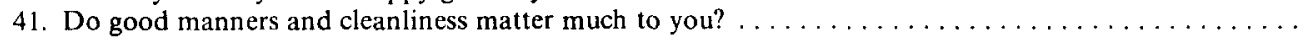

42. Have you often gone against your parents' wishes?

43. Do you worry about awful things that might happen?.

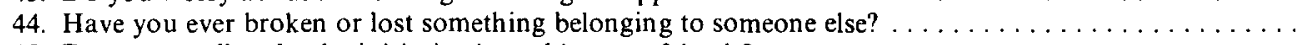

45. Do you usually take the initiative in making new friends?

46. Would you call yourself tense or 'highly-strung'?.

47. Are you mostly quiet when you are with other people?

48. Do you think marriage is old-fashioned and should be done away with? $\ldots \ldots \ldots \ldots \ldots \ldots \ldots \ldots \ldots$

49. Do you sometimes boast a little?.

50. Are you more easy-going about right and wrong than most people? $\ldots \ldots \ldots \ldots \ldots \ldots \ldots \ldots \ldots$

51. Can you easily get some life into a rather dull party?.

52. Do you worry about your health? .

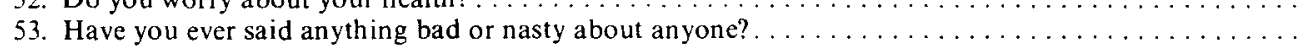

54. Do you enjoy co-operating with others?

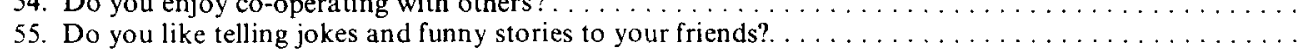

56. Do most things taste the same to you?.

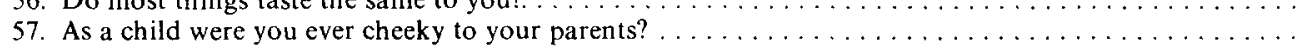

58. Do you like mixing with people?.

59. Does it worry you if you know there are mistakes in your work?

60. Do you suffer from sleeplessness?.

61. Have people said that you sometimes act too rashly?

62. Do you always wash before a meal?.

63. Do you nearly always have a 'ready answer' when people talk to you? $\ldots \ldots \ldots \ldots \ldots \ldots \ldots \ldots \ldots \ldots$

64. Do you like to arrive at appointments in plenty of time?

65. Have you often felt listless and tired for no reason?

66. Have you ever cheated at a game?.

67. Do you like doing things in which you have to act quickly? $\ldots \ldots \ldots \ldots \ldots \ldots \ldots \ldots \ldots \ldots \ldots$

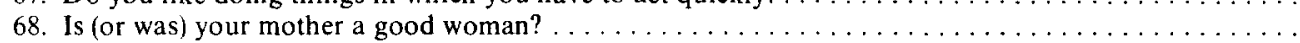

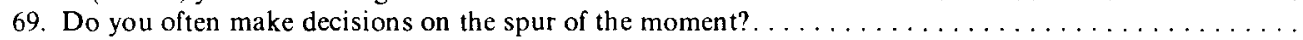

70. Do you of ten fecl life is very dull?

71. Have you ever taken advantage of someone?

72. Do you often take on more activities than you have time for? $\ldots \ldots \ldots \ldots \ldots \ldots \ldots \ldots \ldots \ldots \ldots \ldots$

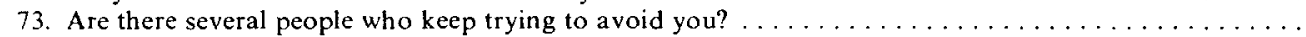

74. Do you worry a lot about your looks?

75. Do you think people spend too much time safeguarding their future with savings and insurance? .....

76. Have you ever wished that you were dead? .

77. Would you dodge paying taxes if you were sure you could never be found out? $\ldots \ldots \ldots \ldots \ldots \ldots$

78. Can you get a party going?

79. Do you try not to be rude to people?

80. Do you worry too long after an embarrassing experience? . . . . $\ldots \ldots \ldots \ldots \ldots \ldots \ldots \ldots \ldots \ldots \ldots$

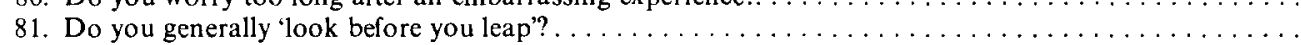

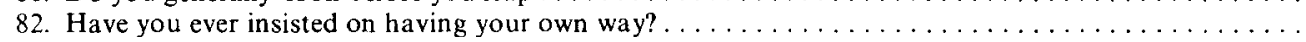

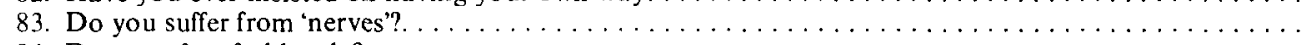

84. Do you often feel lonely? .

85. Can you on the whole trust people to tell the truth?

86. Do you always practice what you preach?.

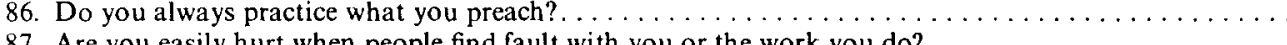

87. Are you easily hurt when people find fault with you or the work you do? $\ldots \ldots \ldots \ldots \ldots \ldots \ldots \ldots$

88. Is it better to follow society's rules than go your own way? $\ldots \ldots \ldots \ldots \ldots \ldots \ldots \ldots \ldots \ldots$

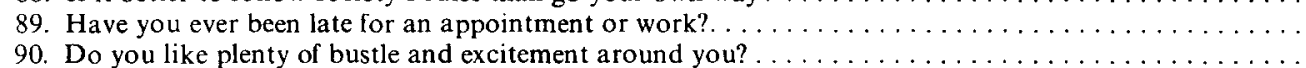

91. Would you like other people to be afraid of you?

92. Are you sometimes bubbling over with energy and sometimes very sluggish? $\ldots \ldots \ldots \ldots \ldots \ldots \ldots \ldots$

93. Do you sometimes put off until tomorrow what you ought to do today?.

94. Do other people think of you as being very lively?

95. Do people tell you a lot of lies?

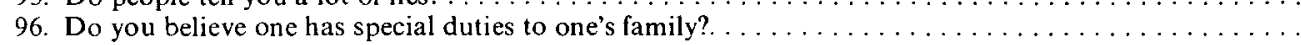

97. Are you touchy about some things?.

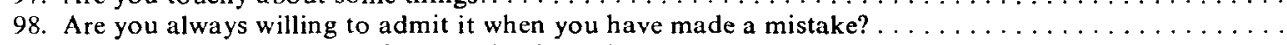

99. Would you feel very sorry for an animal caught in a trap?

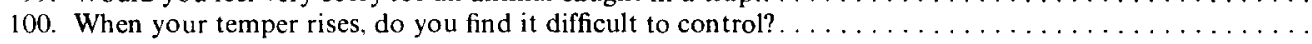

YES

YES

YES

YES

YES

YES

YES

YES

YES

YES

YES

YES

YES

YES

YES

YES

YES

YES

YES

YES

YES

YES

YES

YES

YES

YES

YES

YES

YES

YES

YES

YES

YES

YES

YES

YES

YES

YES

YES

YES

YES

YES

YES

YES

YES

YES

YES

YES

YES

YES

YES

YES

YES

YES

YES

YES

YES

YES

YES

YES

YES

YES

YES

YES

YES

YES

YES

YES
NO 
APPENDIX 2

Short-scale EPQ-R

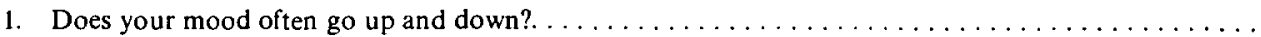

2. Do you take much notice of what people think? . $\ldots \ldots \ldots \ldots \ldots \ldots \ldots \ldots \ldots \ldots \ldots$

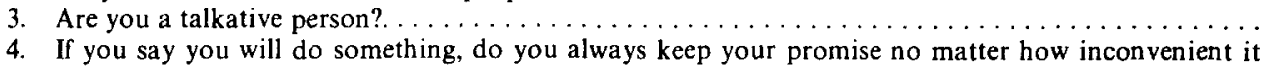
might be? ...

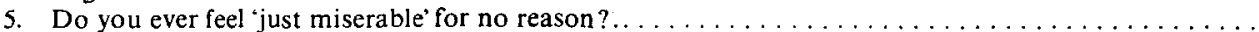

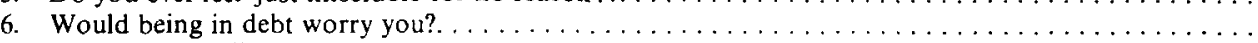

7. Are you rather lively?

8. Were you ever greedy by helping yourself to more than your share of anything? $\ldots \ldots \ldots \ldots \ldots \ldots$

9. Are you an irritable person?

10. Would you take drugs which may have strange or dangerous effects? . . . . . . . . . . . .

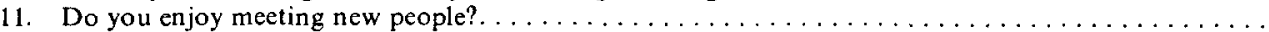

12. Have you ever blamed someonc for doing something you knew was really your fault? ..........

13. Are your feelings easily hurt?

14. Do you prefer to go your own way rather than act by the rules? . . . . . . . . . . . . . .

15. Can you usually let yourself go and enjoy yourself at a lively party? . . . . . . . . . . . . . .

16. Are all your habits good and desirable ones?

17. Do you often feel "fed-up"?.

Do good manners and cleanliness matter much to you?

19. Do you usually take the initiative in making new friends?

20. Have you ever taken anything (even a pin or button) that belonged

.

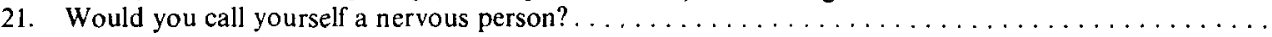

22. Do you think marriage is old-fashioned and should be done away with? . . . . . . . . . . .

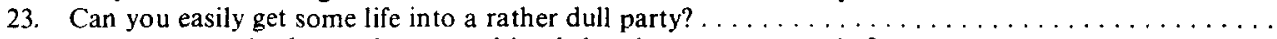

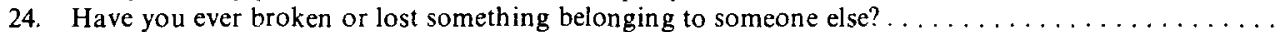

25. Are you a worrier?

26. Do you enjoy co-operating with others?

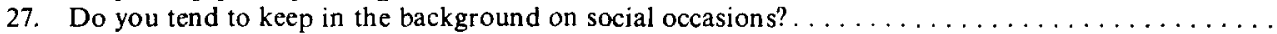

28. Does it worry you if you know there are mistakes in your work? . . . . . . . . . . . . . . .

29. Have you ever said anything bad or nasty about anyone?.

30. Would you call yourself tense or 'highly-strung?

31. Do you think people spend too much time safeguarding their future with saving and insurances?

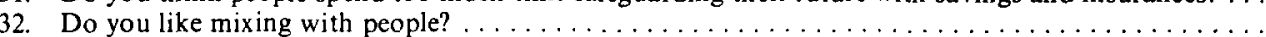

33. As a child were you ever cheeky to your parents? . . . . . . . . . . . . . . . . . . . .

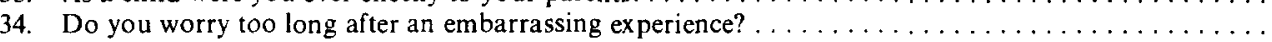

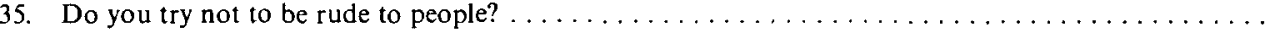

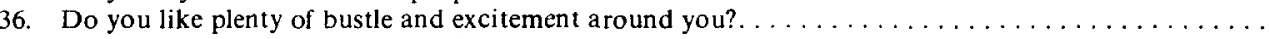

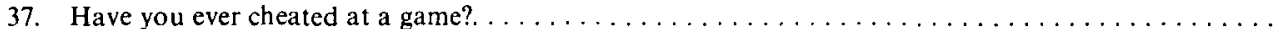

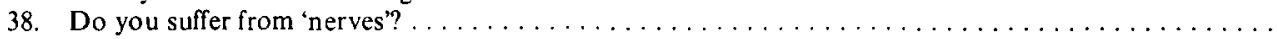

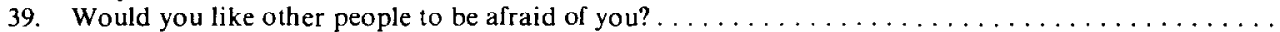

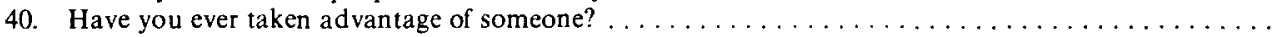

41. Are you mostly quiet when you are with other people? $\ldots \ldots \ldots \ldots \ldots \ldots \ldots \ldots \ldots$

42. Do you often feel lonely?.

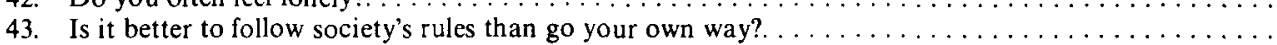

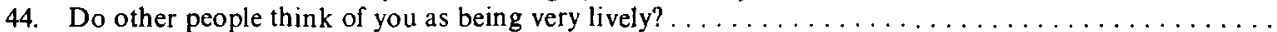

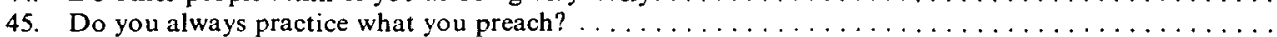

46. Are you often troubled about feelings of guilt?

47. Do you sometimes put off until tomorrow what you ought to do today? $\ldots \ldots \ldots \ldots \ldots \ldots \ldots \ldots$

48. Can you get a party going?

YES NO

YES NO

YES NO

YES NO

YES NO

YES NO

YES NO

YES NO

YES NO

YES NO

YES NO

YES NO

YES NO

YES NO

YES NO

YES NO

YES NO

YES NO

YES NO

YES NO

YES NO

YES NO

YES NO

YES NO

YES NO

YES NO

YES NO

YES NO

YES NO

YES NO

YES NO

YES NO

YES NO

YES NO

YES NO

YES NO

YES NO

YES NO

YES NO

YES NO

YES NO

YES NO

YES NO

YES NO

YES NO

YES NO

YES NO

YES NO 